Erwin Wang, MHA, MD*

Prasad R. Shirvalkar, MD, $\mathrm{PhD*}$

Carolina B. Maciel, MD*

Alexander E. Merkler, MD*

Joseph Safdieh, MD

Ajay Gupta, MD

Neurol Neuroimmunol

Neuroinflammation

2014;1:e30; doi: 10.1212/

NXI.0000000000000030

\section{AMERICAN NEUROBORRELIOSIS PRESENTING AS CRANIAL POLYNEURITIS AND RADICULONEURITIS \\ OPEN}

Lyme disease is a tickborne illness caused primarily by Borrelia burgdorferi in the United States. CNS involvement typically manifests as 1 or a combination of 3 classic syndromes: meningitis, radiculoneuritis, and cranial neuritis. While facial nerve involvement represents about $80 \%$ of cranial neuritis in Lyme neuroborreliosis (LNB), other cranial nerves may also be individually involved; however, multiple cranial nerve involvement is unusual. We report a case of LNB with simultaneous involvement of the third, fifth, sixth, and seventh cranial nerves in addition to cervical and thoracic radiculoneuritis.

Case report. A 56-year-old woman with a history of microscopic colitis presented during the summer with right facial weakness and diplopia. Six weeks prior to presentation, she developed a febrile illness with myalgias, headache, and nasal congestion, with gradual onset of right facial droop, binocular oblique diplopia, and dysarthria over the week prior to admission. In addition, she had cervicothoracic radicular pain over the preceding 6-week period without weakness or dysesthesias.

Her vital signs were normal and head and neck examination was remarkable for injected conjunctiva in the right eye with a decreased blinking rate. She had bilateral incomplete abduction that was worse on the right with associated right-sided ptosis, isocoric pupils, and a lower motor neuron pattern of right facial nerve palsy. She complained of horizontal diplopia on far left and right gaze. In addition, she had decreased sensation to light touch and pinprick in the right trigeminal distribution, as well as weakness in her right masseter.

Serum studies showed elevated white blood cells $(\mathrm{WBC})$ to $16.7 \times 10^{3}$ with neutrophilic predominance, and C-reactive protein was slightly elevated at $1.37 \mathrm{mg} / \mathrm{dL}$ (reference range $0-0.99$ ), as was the erythrocyte sedimentation rate of $43 \mathrm{~mm} /$ hour (reference range 0-30). HIV testing was negative by enzyme immunoassay (ELISA). Serum Lyme total antibody was positive by ELISA. Western blotting for $B$ burgdorferi immunoglobulin (Ig) $M$ antibody revealed the presence of 23 and $41 \mathrm{kDa}$ bands, confirming acute Lyme disease; all IgG bands were negative. MRI of the brain performed prior to CSF sampling demonstrated contrast enhancement of the oculomotor (figure, A), bilateral proximal trigeminal (figure, B), abducens, and facial nerves (figure, C). In addition, MRI of cervical and thoracic spine showed leptomeningeal enhancement in several ventral and dorsal nerve roots (figure, D).

CSF analysis revealed an opening pressure of $23 \mathrm{~mm}$ $\mathrm{H}_{2} \mathrm{O}$ and 67 WBC with $87 \%$ lymphocytes, 6 red blood cells, glucose of $43 \mathrm{mg} / \mathrm{dL}$ (serum $108 \mathrm{mg} / \mathrm{dL}$ ), and protein of $179 \mathrm{mg} / \mathrm{dL}$. CSF varicella-zoster virus PCR, cytology, and flow cytometry were all negative. Angiotensin-converting enzyme levels were normal in the CSF and serum. CSF was positive for Lyme antibody by ELISA.

She demonstrated a significant clinical response to ceftriaxone, with resolution of ophthalmoplegia and marked improvement of facial palsy. Corticosteroid administration was deferred given her subacute presentation. Repeat MRI 1 month later showed resolution of cranial nerve enhancement and marked decrease of cervicothoracic nerve root enhancement (images not shown).

Discussion. We report a case of American LNB involving cranial polyneuritis and painful cervicothoracic radiculitis. Lyme disease is caused by an array of spirochetes and may produce different clinical manifestations based on regional variations in the spirochete species. ${ }^{1}$ In North America, the most common species is $B$ burgdorferi, while European or Asian Lyme disease can be caused by up to 5 different species, most often $B$ afzelii or $B$ garinii. ${ }^{1}$

While less than $10 \%$ of patients with Lyme disease in the United States manifest with neurologic symptoms, more than $35 \%$ of European patients with Lyme disease have neurologic involvement. ${ }^{2}$

Cranial polyneuritis is relatively uncommon in American neuroborreliosis, occurring in $16 \%$ of cases, $80 \%$ of which involve solely the facial nerve. ${ }^{3}$ In contrast, the incidence of cranial neuritis is more than $35 \%$ in Europe. ${ }^{2}$ One large international case series demonstrated that among patients with cranial nerve involvement only $15 \%-20 \%$ had involvement of more than one cranial nerve. ${ }^{4}$ In addition, of the case reports 
Figure Widespread leptomeningeal enhancement

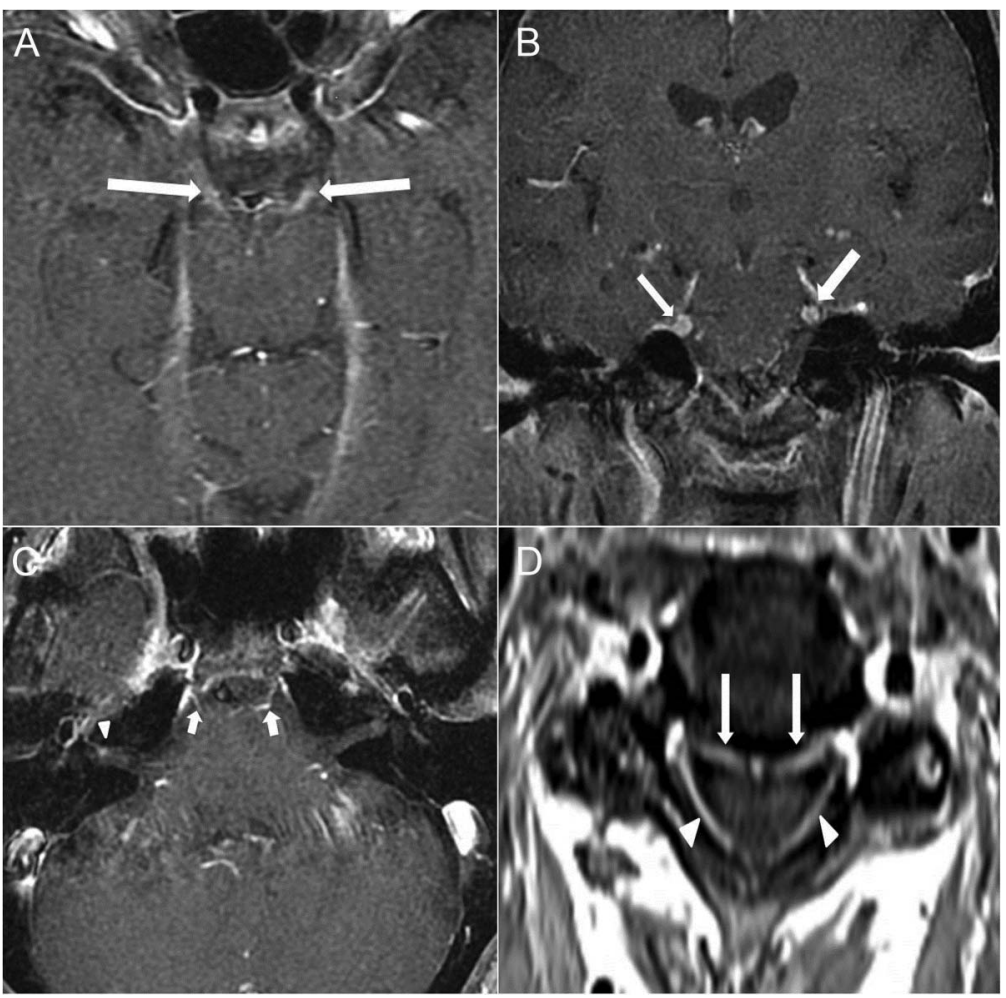

Axial T1 fat-saturated postcontrast image (A) demonstrates abnormal leptomeningeal enhancement of bilateral cranial nerve III (arrows). Coronal T1 fat-saturated postcontrast image (B) shows abnormal leptomeningeal enhancement of bilateral cranial nerve $\mathrm{V}$ (arrows) near the root entry zone. Axial T1 fat-saturated postcontrast image (C) demonstrates abnormal smooth leptomeningeal enhancement of bilateral cranial nerve VI (arrows) and focal nodular enhancement of left cranial nerve VII (arrowhead) in the fundus of the internal auditory canal. Axial T1 fat-saturated postcontrast image (D) through the cervical spine demonstrates abnormal leptomeningeal enhancement of the ventral (arrows) and dorsal (arrowheads) roots of the cervical spinal cord.

discussing cranial polyneuritis due to American Lyme disease, few describe involvement of more than 2 cranial nerves per patient.,

Radiculoneuritis is more prevalent in the European form, affecting more than $50 \%$ of patients. In contrast, monoradiculoneuritis is observed in only $4 \%$ of American cases based on aggregate Centers for Disease Control and Prevention data, and the incidence of polyradiculoneuritis is likely even less common. ${ }^{7}$

In summary, there is sparse literature describing American LNB associated with cranial polyneuritis and polyradiculitis. We hope to make physicians aware that, although unusual, American neuroborreliosis may indeed present with cranial polyneuritis and polyradiculitis.

* These authors contributed equally to the manuscript. From the Departments of Neurology (E.W., P.R.S., C.B.M., A.E.M., J.S.) and Radiology (A.G.), Weill Cornell Medical College, New YorkPresbyterian Hospital, New York, NY.

Author contributions: Erwin Wang, MHA, MD conceived and designed the study and drafted and revised the manuscript for intellectual content. Prasad R. Shirvalkar, MD, PhD conceived and designed the study and drafted and revised the manuscript for intellectual content. Carolina B. Maciel, MD conceived and designed the study and drafted and revised the manuscript for intellectual content. Alexander E. Merkler, MD conceived and designed the study and drafted and revised the manuscript for intellectual content. Joseph Safdieh, MD revised the article critically for important intellectual content. Ajay Gupta, MD designed the study and revised the article critically for important intellectual content.

Study funding: No targeted funding reported.

Disclosure: E. Wang, P.R. Shirvalkar, C. Maciel, and A.E. Merkler report no disclosures. J. Safdieh receives publishing royalties from Elsevier, receives research support from Accera, and provides legal expert work. A. Gupta is a section editor for Radiology Case Reports and receives research support from the NIH, Association of University Radiologists Foundation Award, and GE-AUR Research Academic Fellowship Award. Go to Neurology.org/nn for full disclosures. The Article Processing Charge was paid by the authors.

This is an open access article distributed under the terms of the Creative Commons Attribution-Noncommercial No Derivative 3.0 License, which permits downloading and sharing the work provided it is properly cited. The work cannot be changed in any way or used commercially.

Received May 16, 2014. Accepted in final form August 5, 2014.

Correspondence to Dr. Maciel: carolbmaciel@gmail.com

1. Stanek G, Wormser GP, Gray J, Strle F. Lyme borreliosis. Lancet 2012;379:461-473.

2. Hildenbrand P, Craven DE, Jones R, Nemeskal P. Lyme neuroborreliosis: manifestations of a rapidly emerging zoonosis. AJNR Am J Neuroradiol 2009;30:1079-1087.

3. Pachner AR, Steere AC. The triad of neurologic manifestations of Lyme disease: meningitis, cranial neuritis, and radiculoneuritis. Neurology 1985;35:47-53.

4. Halperin JJ. Lyme disease and the peripheral nervous system. Muscle Nerve 2003;28:133-143.

5. Greer DM, Schaefer PW, Plotkin SR, Hasserjian RP, Steere AC. Case records of the Massachusetts General Hospital. Case 11-2007. A 59-year-old man with neck pain, weakness in the arms, and cranial-nerve palsies. N Engl J Med 2007;356: 1561-1570.

6. Abul-Kasim K. Neuroborreliosis with enhancement of the third, fifth, sixth, and twelfth cranial nerves. Acta Neurol Belg 2010;110:215.

7. van Erp WS, Bakker NA, Aries MJ, Vroomen PC. Opsoclonus and multiple cranial neuropathy as a manifestation of neuroborreliosis. Neurology 2011;77:1013-1014. 